\title{
Pre-Service Elementary Teachers' Experiences, Expectations, Beliefs, and Attitudes toward Mathematics Teaching and Learning
}

\author{
Roland G. Pourdavood, Ph.D. and \\ Xiongyi Liu, Ph.D. \\ Cleveland State University (CSU) \\ Cleveland, Ohio, USA
}

\begin{abstract}
Many elementary pre-service teachers (PSTs) have negative experiences regarding learning mathematics. They carry these prior negative experiences with them as they take their mathematics methods courses for teaching young children and they express their lack of confidence in teaching mathematics. This qualitative and descriptive study describes 23 elementary PSTs' stated experiences, expectations, beliefs, and attitudes toward mathematics during their K-12 schooling and college mathematics courses. The study examines how a semesterlong methods course in mathematics provides these PSTs an opportunity to re-evaluate their assumptions about what mathematics is and the role of teachers and learners in mathematics classrooms. In addition, the study describes the challenges that the primary researcher and the instructor of the course face. It illustrates the strategies he uses to accommodate PSTs' professional transformation. Data was collected throughout participants' enrollment in a semester-long course called Mathematics Instruction in Preschool and the Primary Grades, which was taken in conjunction with their practicum. Data sources included university classroom observations, pre-service teachers' verbal and written responses to class discussions, reading assignments, course activities, presentations, and a final reflective paper. PSTs' responses were categorized and common themes were derived from the triangulation of data to include prospective teachers' critical reflections on teaching and learning, transformation of their stated beliefs and attitudes toward mathematics, and their concerns and struggles.
\end{abstract}

Keywords: Pre-service teachers; constructivism; mathematics education.

\section{Introduction}

Ideas about what mathematics is and is not may have a strong influence on the teachers' and learners' experiences, expectations, beliefs, and attitudes toward mathematics teaching and learning. Many people are convinced that they can 
never learn mathematics. Psychologists call this attitude, "learned helplessness." They define learned helplessness in the mathematics education context as a pattern of beliefs whereby learners attribute failure to limitations of ability (McLeof \& Ortega, 1993). McLeof \& Ortega (1993) compared learned helplessness with "mastery orientation," in which learners have confidence in their ability to solve challenging problems. Learned helplessness is negatively correlated with persistence, while mastery orientation is positively related to persistence.

Psychologists also found that this conception of the ability to learn can be modified by social context. They describe how classroom conversations can encourage a learner to be more confident in their ability to solve problems. Such positive beliefs can also be developed through positive experiences of persistence in problem solving. Sometimes, characterizing a problem as "easy" can profoundly demoralize learners, because from their point of view it may be difficult. The National Council of Teachers of Mathematics (NCTM) calls a learner's attitudes and self-confidence toward mathematics a mathematical disposition (NCTM, 2000). Some researchers define mathematical disposition as interest in, appreciation for, and persistence into mathematics (Briley, 2012). Mathematical disposition also includes confidence, curiosity, perseverance, flexibility, inventiveness, and reflectivity. A strong mathematical disposition is important for learning and understanding mathematics and can be developed if mathematics is presented in a real world context.

To learn more about real world contexts, this study examined 23 elementary preservice teachers' (PSTs) reported experiences, expectations, beliefs, and attitudes toward mathematics from Kindergarten through their college mathematics courses. The study explores how a semester-long mathematics methods course provides these PSTs an opportunity to re-evaluate their prior beliefs and attitudes toward mathematics. The primary researcher and the instructor of the course describe the challenges faced during the semester such as PSTs' lack of confidence in learning mathematics, fears of standing in front of the classroom teaching mathematics, and prior experiences relative to the role of teachers and students in the mathematics classroom. To face these challenges, the instructor designs the course to provide opportunities for PSTs to reconstruct their prior assumptions through reflective readings, reflection of personal philosophy, writing and solving non-routine problems, cooperative learning, and use of manipulatives and technology for teaching and learning mathematics. The primary researcher communicates with the PSTs regarding roles and expectations relative to mathematics classroom culture and spends extra times with PSTs at risk of failing the course. The study is context specific and does not intend to generalize the findings (i.e. 23 PSTs in one mathematics methods course). It is the researchers' hope that sharing the study's challenges, strategies, and findings will engage educational communities in reflection of their beliefs and attitudes toward teaching and learning mathematics and providing opportunities for their students' personal and professional transformation. The primary research question is, "How may a semester-long methods course in mathematics provide opportunities for PSTs to transform their expectations, 
attitudes, and beliefs as they take more participatory roles in their mathematics methods course?"

\section{Literature Review}

Pre-service elementary teachers' (PSTs) attitudes toward teaching and learning mathematics are influenced by their prior mathematics education experiences in K-12 schooling (Jong \& Hodges, 2013; Itter \& Meyers, 2017; Stohlmann, Cramer, Moore, \& Maiorca, 2014; Xenofontos \& Kyriakou, 2017). However, mathematics methods courses that are part of teacher education programs can serve to improve the attitudes of PSTs (Burton, 2012; Jong \& Hodges, 2013; Jong \& Hodges, 2015; Stohlmann et al., 2014). In their study, Stohlmann et al. (2014) provided PSTs opportunities to transform their attitudes toward a conceptual rather than procedural understanding of mathematics. This shift is important as it shows that PSTs can be given teaching and learning models that present a better understanding of principles, roles of teachers and learners in mathematics classrooms, and the connections among interrelated concepts in mathematics classrooms, rather than just reviewing sequences of procedures for solving problems. Research shows that mathematics methods courses designed specifically to impact elementary PSTs confidence and motivation in relation to mathematical content knowledge (M-CK) and mathematical pedagogical content knowledge (M-PCK), are more likely to do so than PSTs who did not participate in the courses (Cardetti \& Truxaw, 2014). It has been hypothesized that increases in attitude toward M-CK and M-PCK will increase teachers' self-efficacy, which is thought to be related to teacher efficiency and effectiveness (Cardetti \& Truxaw, 2014).

Similarly, research showed that elementary PSTs have little knowledge of the value of multiple representations in mathematics education (Dreher \& Kuntze, 2015; Dreher, Kuntze, \& Lerman, 2016; Özmantar et al., 2010). There is evidence that teachers in general and PSTs in particular see multiple representations as a method to motivate students to learn mathematics in a fun way rather than a tool to enhance conceptual understanding of mathematical ideas. They often minimize the need to explain connections among different representations explicitly, which is necessary for students' understanding of mathematical procedures (Dreher \& Kuntze, 2015). The accepted notion that an understanding of the interrelatedness of different representations is essential in order to thoroughly understand mathematical concepts sets an important target for further research and professional development (Dreher \& Kuntze, 2015; Dreher, Kuntze, \& Lerman, 2016). Furthermore, Dreher \& Kuntze (2015) recognize a need for research into how domain-specific content knowledge influences PSTs' views of how to utilize multiple representations meaningfully.

Briley (2012) examined the connections between mathematics teaching efficacy, mathematics self-efficacy, and mathematical beliefs in 95 elementary PSTs with the use of surveys. PSTs with more sophisticated beliefs in regards to doing, validating, and learning mathematics, as well as beliefs about the usefulness of mathematics, tended to have higher mathematics teaching efficacy, which had a statistically positive relationship to mathematics self-efficacy. Since 
mathematics-teaching efficacy is essential for positive performance as a teacher, the author suggested that teacher educators ought to evaluate and facilitate, if necessary, the transformation of PSTs' beliefs and attitudes toward mathematics.

\section{Theoretical Framework}

The theoretical assumption of this study is grounded in social constructivist perspective (Cobb, 1994; Cobb \& Yackel, 1996). "Learning is a constructive process that occurs while participating in and contributing to the practices of the local community" (Cobb \& Yackel, 1996, p.185). The primary researcher and instructor of the course believe that a constructivist approach is reflected in the instructor's classroom activities and instructional practices. He believes teaching and learning are constructed individually, as well as socially, while participating in the activities of the classroom learning community (i.e., cooperative learning and partnership). His intention is to create a learning environment where his PSTs can get a sense of constructivism in action.

To incorporate constructivist beliefs in his classroom practices, he employs several strategies. First, he uses small group cooperative learning to create learning opportunities for PSTs to build their own meaning of mathematical procedures (i.e., inquiry, contextualism, and partnership). Second, he requires the PSTs to write non-routine, open-ended problems (inquiry-based mathematics). Writing encourages PSTs to take risks and reflect. Third, he attempts to create a supportive learning climate in the classroom by spending the first couple of weeks in class discussing with PSTs about roles and course expectations. This discussion is ongoing. Fourth, he continually tells the PSTs they are capable mathematicians who can do mathematics and create relevant mathematical problems. Fifth, he encourages and facilitates PSTs' discussion and active listening (professionalism). In problem-solving situations, he expects his PSTs to restate what the problem is asking, articulate how they are interpreting the problem, model their solution (visualization), and write about their thinking, reasoning, and computation. The above method of instruction is crucial for his classroom community to experience constructivism in practice.

Although there are a variety of constructivist frameworks (Hennessey, Higley, \& Chestnut, 2012), there is general agreement in the mathematics education community that constructivist practices are more viable to educate our future mathematics teachers and promote alignment with the standards put forth by the NCTM (Briley, 2012; Kalchman, 2011; Narli, 2011; Zain, Rasidi, \& Abidin, 2012). Traditionally, learning in school occurs in a teacher-centered environment, in which the teacher is the center of attention and tells the students what they need to know and do (Zain, Rasidi, \& Abidin, 2012). However, constructivism calls for approaches to learning that are student-centered and focused on inductive learning and discovery. In constructivist classrooms, students are active learners and construct ways of knowing that would make sense to them (Garcia \& Pacheco, 2013; Zain, Rasidi, \& Abidin, 2012). Ample evidence exists that constructivist teaching leads to better learning outcomes. 
Studies have also shown that constructivist learning environments lead to better real-world connections, helping students realize how much mathematics is a part of their lives outside of school (Kalchman, 2011; Zain, Rasidi, \& Abidin, 2012). This is important because "students learn best when they are able to relate what they learn in the classroom to the immediate environment and create meaning from different experiences" (Zain, Rasidi, \& Abidin, 2012, p. 324). This heightened ability to form connections, along with a wider variety of learning practices (kinesthetic, visual, and auditory) is significant for learning mathematics. In addition, an emphasis on cooperative learning from teams and peers promotes a high degree of participation and in result, a high degree of retention (Narli, 2011; Zain, Rasidi, \& Abidin, 2012). Perhaps most importantly, students also report that learning in a constructivist manner is enjoyable, more interesting than traditional approaches, and leads to better understanding of abstract concepts (Garcia \& Pacheco, 2013). As for teacher education, Briley (2012) found the reflection that is involved in constructivist learning was sufficient to produce positive change in PSTs' mathematical beliefs, mathematics self-efficacy, and mathematics teaching efficacy. Clearly, movement from teacher-centered learning environments toward constructivist, student-centered learning environments, can make a profound positive impact in our education system at all levels, particularly in the area of mathematics education.

\section{Context of the Study Participants}

The study is conducted in a state-supported university located in a large metropolitan area in Midwestern America. The course has a dual numbered section that includes both graduate and undergraduate students. There were 23 students in the classroom in the fall of 2016 (20 females and 3 males). Twentyone students were undergraduates and two were graduates. Four of 23 students were undergraduate special education majors with emphasis on mild/moderate intervention specialty and only one of them was doing her practicum in a suburban school setting. The other 19 students were in the early childhood program, 14 of which were doing their practicum during the course in different school settings, six PSTs were in pre-k-kindergarten classrooms (four in urban settings and two in suburban), and eight PSTs were in 1st-3rd grade classrooms, in urban settings. All participants were enrolled in a three-credit, semester-long methods course called Mathematics Instruction in Preschool and the Primary Grades. This course focuses on development of a sound rationale for teaching and learning mathematics that takes into account the constructive processes that young children need to acquire numeracy and problem-solving strategies. The 23 prospective teachers who participated in this study ranged from 20 to 30 years old. While 20 (87 percent) of the participants were female, the class was ethnically and racially diverse including five Black or African Americans, three Hispanic or Latino students, two Asians, and two Middle Eastern students. The remaining eleven individuals were White and of European descent. The course meets once a week for three hours per meeting and is often taken in conjunction with a field-based practicum. During the fall of 2016, 15 of the enrollees were concurrently completing a 240-hour practicum in a preschool or primary school setting. The instructor and primary researcher of this study has been teaching 
mathematics methods for 21 years and has experience supervising PSTs in the field.

Registration for the course requires prior completion of a sequence of three mathematics courses with a grade $\mathrm{C}$ or better. The three mathematics courses are Mathematics for Elementary Teachers I, II, and III, also known as MTH 127, MTH 128, and MTH 129. MTH 127 focuses on numeration systems and whole number arithmetic, integers and number theory, rational and real numbers, problem solving, and applications. MTH 128 is the second course in the three courses sequence designed to provide the interns opportunity to have a better understanding of geometry, congruence, symmetry, similarity, and coordinating geometry. MTH 129, the last course in the sequence, includes topics relative to measurement, probability, and statistics along with appropriate use of elementary classroom technology.

\section{Design}

Mathematics Instruction in Preschool and the Primary Grades provides prospective teachers an opportunity to consider and evaluate various philosophies, principles, practices, and problems associated with teaching mathematics in preschool and primary grades. One of the required textbooks is a course packet designed and developed by the primary. The course packet is an evolving resource for him and for his students in the sense that the contents of the course packet changes in order to accommodate students' needs. The contents of the course packet include short articles and activities about the history of teaching and learning mathematics, co-operative learning, assessment, and non-routine problems relative to NCTM contents and processes. The rationale for using his own course packet as a required text is to model the importance of reflectivity, professionalism, contextualization, and inquiry. The cost of the course packet is covered as a part of their lab fee (\$35) that they pay when they enroll for the course. The rest of the lab fee goes towards overhead manipulatives such as Base-10-Blocks, Square Tiles, Pattern Blocks, Tangram, Cuisenaire Rods, and Geoboards. They keep their course packet and manipulatives with them as their instructional resources at the end of each semester.

The other required text is: Putting it Together: Middle School Math in Transition by Tsuruda (1994). The students receive the book free in the beginning of each semester and are required to return it by the end of each semester. The rationale for using Tsuruda's book is that the author talks about his professional story of transformation from being predominantly behaviorist to more constructivist in his beliefs and practices. He describes how the "seed of change" and "paradigm shift" occurred in his experience. He asserts that it took him 15 years to change his approach to teaching and learning mathematics. He argues that his own systematic reflection on his teaching and his students' learning, his exchange of ideas and information with his school colleagues, and his participation in and contribution to the national organizations such as the National Council of Teachers of Mathematics (NCTM), are key factors of his evolution. Tsuruda's professional story is interesting and inspiring for all preK-12 teachers to hear and to reflect on. In addition to the required textbooks, participants must read 
and reflect on at least eight current research articles relative to early childhood teaching and learning mathematics as selected by the instructor. Collectively, these readings provide the basis for classroom discussion and reflection.

Other assignments and activities of the course include writing a statement describing the intern's initial personal philosophy of teaching, learning, and assessing mathematics; designing and presenting their lesson plan in collaboration with other members of their group; writing an assessment letter to a parent communicating how they would assess their children's mathematical learning; searching and evaluating internet resources relative to teaching and learning mathematics for early childhood classrooms; creating non-routine problems appropriate for early childhood classrooms; completing a comprehensive problem solving exam, demonstrating their content knowledge of mathematics; and revisiting their initial personal philosophy paper and writing a reflective final paper about teaching, learning, assessment, and the use of technological tools in mathematics classrooms. In addition, PSTs are required to submit their portfolios that demonstrate their semester-long performance and accomplishments for the course. The contents of portfolio include: a table of contents, a summary letter regarding who the author is and what is in the portfolio, and all of the course assignments organized by the author of the portfolio.

Major themes of the course include: mathematics as an activity of constructing and perceiving patterns and relationships; problem-centered learning, sharing solutions and negotiating meaning; writing as a vehicle for developing thinking, reasoning, and expressive abilities; and the role of technology in mathematics learning. Finally, as a vehicle for promoting culturally-responsive pedagogy that contributes to children's confidence, sense of purpose, and well-being, participants are challenged to employ teaching strategies that support intellectual engagement, connectedness to the wider world, and respect for diversity. To this end, PSTs are empowered to examine and identify the relative strengths and limitations of various strategies for structuring constructivist teaching learning environments that facilitate: problem-based, student-centered learning; problem solving; reasoning and critical thinking; mathematical communication; mathematical modeling; and collaboration.

\section{Classroom Culture}

In Mathematics Instruction in Preschool and the Primary Grades, the primary researcher and instructor of the course is frequently dealing with PSTs who enter the classroom with low self-esteem and low self-confidence around teaching and learning mathematics. Although, all PSTs pass the sequence of mathematics prerequisite courses, demonstrating their competence in teaching elementary school mathematics, most of them remain unconfident teaching it. They fear that they lack pedagogical content knowledge to teach young children. They bring these attitudes with them into their mathematics methods course classrooms. They carry the belief that they are not good at mathematics; they think they cannot do mathematics; they do not like mathematics; mathematics is something they think people either know or do not know. Sometimes, they say 
similar comments to, "I'm going to teach elementary students, so why do I need to know this?"

The first challenge for the primary researcher and the instructor of the course each semester is to debunk the myths they bring with them and to create an environment in which they can safely question their prior assumptions about mathematics. He starts from the beginning by posing questions that are relevant to their experiences and open-ended. For example, in the beginning of each semester, he model a problem-centered classroom and continues this modeling throughout the semester so PSTs can see how it works and how they may use this strategy for teaching mathematics. One example of a problem-centered classroom activity is presented below. Consider these three problems:

1. A person takes a 5,000 miles trip in his/her car. He/she rotates his/her tires ( 4 on the car and one spare) so that at the end of the trip, each tire is used for the same number of miles. How many miles are driven on each tire? Use any strategy and communicate your solution.

2. A farmer needs to take his goat, wolf, and cabbage across the river. His boat can only accommodate him and either his goat, wolf, or cabbage. If he takes the wolf with him, the goat will eat the cabbage. If he takes the cabbage, the wolf will eat the goat. Only when the man is present, are the cabbage and goat safe from their respective predators. How does he get everything across the river? Communicate your thinking and reasoning. (Adapted from Pappas's Book entitled: the Joy of Mathematics, 1986, p. 159).

3. A person bought a horse for $\$ 50$ and sold it for $\$ 60$. He/she then bought the horse back for $\$ 70$ and sold it again for $\$ 80$. What do you think was the financial outcome of these transactions? Explain your Reasoning.

These problems are interesting for our PSTs, as they discover that they do not need to memorize mathematical roles to solve these problems. They want to figure out solutions to these problems in their ways. Problem-centered strategy, which the primary researcher and the instructor uses, is very effective relative to the PSTs' change of attitudes and beliefs toward mathematics teaching and learning. The problem-centered classroom has three components: (1) a task that is interesting and requires mathematical thinking and processing, (2) small group cooperative learning (4 to 5 interns in each group), (3) whole class discussions and presentations of multiple solutions/ perspectives. Throughout the semester, the primary researcher communicates with his PSTs regarding his expectations relative to their participation in and contribution to the classroom activities. When PSTs are working together, they are first expected to provide support for each, then communicate their solution to others struggling to understand and if they still have an issue, ask the teacher/the instructor for help, if the question is the group's question.

By establishing and communicating with PSTs his expectations, they develop and understanding of how a problem-centered classroom works. During 
problem solving activities, they are advised to: restate what the question is asking or how they are interpreting the problem; to use a variety of strategies for gathering information about the problem such as drawing, making a diagram, building a chart, using manipulatives such as play money or Base-10-Blocks, for mathematical modeling and representations. It is necessary and required to be able to communicate both verbally and in writing regarding how they solve the problem. The primary researcher encourages discussions and multiple representations during the problem solving situations. He values the PSTs' thinking processes and encourage risk-taking. In addition, as a classroom instructor, he models the importance of active listening, asking questions, wait time for connecting with children's responses, and authentic assessment. $\mathrm{He}$ uses this mathematical teaching model throughout the semester in order to illustrate constructivism in action.

The second challenge for him as an instructor of the course is reaching all of the PSTs, especially those who are at risk of failing the course. One way to face the challenge and accommodate/enhance those PSTs learning experience in the methods course is to spend extra time with them before class, after class, and to continue ongoing conversation with them via email communication. Spending extra time with struggling PSTs seems to be an effective strategy for engaging them in learning and facilitating their success in the course.

When PSTs reach the realization that they do not have to memorize formulas in order to solve problems, they become more confident in their own abilities to think independently and defend their solutions. When the primary researcher sees them reaching that point, when he sees the light bulbs come on and sees their joy of doing significant mathematics, he feels he have succeeded in positively impacting someone else's life. He believes there are more of these moments now, than there were when he began teaching the course 21 years ago. Through the process of interaction with his PSTs, he have become an observer of himself and his participants (i.e. reflective inquiry). He have used their feedback and his own systematic reflection of his teaching to reconstruct his course packet, these strategies and inquiries are consistent with the spirit of NCTM $(2000,1995,1991,1989)$ and constructivist epistemology.

Another sample of our classroom activities is that the PSTs are required to develop a lesson plan, a lesson presentation, and group project appropriate for the preK-3 level. The primary researcher and the instructor of the course provides them with guidelines regarding their lesson plans and presentations. Each group consists of four or five members. In order to facilitate their group project productively, he asks the PSTs not to change their group once they have started working and developing their lesson plan. In their small group, the PSTs have opportunities to interact, negotiate, and make decision three times during the instructional time per semester, for about 40 minutes each time. In addition, the PSTs are encouraged to exchange ideas and information via internet for further communication prior to their group lesson presentation. During the inclass discussions, PSTs' tasks are to make decisions about: (1) who will be the team leader, (2) who will teach which grade level, and (3) what theme to use for 
the content that they intend to teach. They need to provide a rationale, communicating why it is important to learn this lesson. The theme should put their mathematics content in a meaningful context so that their lessons flow seamlessly and are developmentally appropriate for each grade level following the State Common Core Standards. For example, if a team decides to teach measurement content standards for preK-3rd grades, they may think about a context such as designing a playground or designing a room. Then, they need to develop their lesson plans following the State Common Core Standards for pre-k$3^{\text {rd }}$ grades. The job of the team leader is to make sure that the collective lessons are submitted to the instructor on time prior to their teaching so that PSTs have opportunity to modify their lessons if needed. The PSTs working in groups of four or five, teach their lessons to the class (10-15 minutes for each lesson presentation, maximum 75 minutes for the group). Coherency and interconnectedness of the group project is very important. The lesson presentations should be hands-on, inquiry-based, student-centered, and interactive. A lesson may focus on a mathematical game, puzzle or problemsolving activity, numbers and operation, geometry, measurement, probability, and early concepts of algebra. They are encouraged to use technology for finding and adapting ideas and activities for their lessons. They are asked to use Internet resources with clear references and connection to the origin of the lesson. Before and after lesson presentation the PSTs receive feedback from the instructor as well as their cooperative group members regarding the strengths and weaknesses of their lesson plans and their presentations. In addition, the lessons ought to include accommodations for Learners with Varying Abilities and Exceptionalities (VAE), Emergent Bilingual Learners (EBL), and Gifted Learners (GL). Furthermore, after lesson presentation, they are required to write a narrative, analyzing their own teaching.

\section{Methodology}

A number of researchers indicate a need for future research to include more qualitative data relative to PSTs' experiences, expectations, beliefs, and attitudes toward mathematics (Briley, 2012; Burton, 2012; Cardetti \& Truxaw, 2014; \& Dreher et al., 2016). Briley (2012) posited that qualitative data could add richness and clues to complexities of our current understanding of the relationships between mathematics teaching efficacy, mathematics self-efficacy, and mathematical beliefs. Similarly, Burton (2012), who researched the ability of certain content methods courses to change PSTs' attitudes toward mathematics, suggested that qualitative data could provide valuable information on different factors that influence the change process that occurs in PSTs. Cardetti and Truxaw (2014) and Dreher et al. (2016) presented suggestions in line with the previously outlined, asserting that qualitative data would provide details that quantitative data fails to capture.

This qualitative research study is grounded in constructivist inquiry (Guba \& Lincoln, 1989; 1994; Lincoln \& Guba, 1985). This methodology is consistent with the theoretical framework of our research study. A constructivist views reality as local and context-specific. As such, reality, according to constructivists, is shaped by experience and social interactions. Such a perspective sees the 
relationship between knower and known as dialectical and suggests that researcher and the researched interact and are interconnected. It is impossible, therefore, to distinguish cause from effect. The constructivist questions the generalizability of any research finding in positivist terms, arguing that research is value-dependent.

Guba and Lincoln $(1989 ; 1994)$ suggested the approaches for establishing trustworthiness of interpretation and analysis of research findings. They focused on four criteria namely credibility, transferability, dependability, and conformability. Credibility refers to certain activities that increase the probability that the findings will be authentic. One such activity is investment of time. It is imperative that the inquirer spend time becoming oriented to the situation. There is no answer as to how much time is needed for becoming familiar with the research study. One indication of credibility is acceptance of the findings by all participants, including the researchers. Data, analytic categories, interpretations, and findings must be examined by the members who provided the information to prove it's credibility. Lincoln and Guba (1985) called this "member checking". Member checking continually occurs through the data collection process and is an important component of credibility. The second component of trustworthiness is transferability. Transferability refers to the potential for others to identify with the research context and apply the findings to their own particular situation. Transferability is obtained through the provision of "thick description" (McCracken, 1988; Guba \& Lincoln, 1989; 1994; Lincoln \& Guba, 1985). The third component of trustworthiness is dependability. Lincoln and Guba (1985) describe dependability as a means of establishing reliability. Dependability can be established in two ways: through the use of inquiry teams or the use of the audit. An auditor examines the process by which the data was collected and is closely connected to conformability, the fourth component of trustworthiness. Therefore, we, the researchers, used constructivist methodology to investigate the relationship between PSTs' prior experiences, expectations, attitudes, and beliefs toward mathematics learning when they were in K-12 schools and their current attitudes and beliefs as they participate classroom activities.

\section{Data Collection and Data Analysis}

Data collection and data analysis for this research are from the fall semester of 2016 and were gathered from 23 college students. Data sources include university classroom observations, pre-service teachers' verbal and written responses to questions, verbal and written discussions, reflections on reading assignments and course activities, presentations, and a final reflective paper. Most data presented in this paper focuses on pre-service teachers' written responses to three questions presented in the beginning of the semester, reflections on classroom activities and discussions, and their final reflective papers. I, the instructor of the course and the primary researcher, acted as a participant-observer, a facilitator, and a coach in the classroom. The on-going process of sharing my understanding and interpretations of the findings with interns (i.e., triangulation of data processing) played an important role for establishment of a caring community and trustworthiness. Triangulation 
occurred in three ways. First, we triangulated data via an on-going conversation with interns before and after each class meeting or during the following week's class after reading their papers. Second, we triangulated data by comparing multiple data sources (i.e., reading reflections, classroom discussions, observations, and one-on-one conversations). Third, we triangulated data through member checking (i.e., exchange of ideas among the researchers).

Data collection and data analysis occurred simultaneously throughout a semester-long course that aims to provide conceptual understanding of mathematical ideas and enable the participating pre-service teachers to enact these perspectives and contexts throughout their pedagogy. Data was continually compared, applying a constant comparative method (Lincoln \& Guba, 1985). Based on emergent patterns and themes, several factors were identified as being important considerations in regards to PSTs' professional transformation. The research methodology, data collection, and data analysis are characterized by the following features suggested by Bogdan \& Biklen (1982): (1) a natural setting as the direct source of data; (2) the researcher as "developer"; (3) the research as descriptive; (4) researchers' concern for process over outcomes and product; (5) inductive analysis; (6) analysis supported by phenomenological theory which accepts multiple realities and suggests change is the result of an individual's thoughts and ideas; and (7) meaning as the essential concern.

\section{Constructing Meaning from the Data}

In the beginning of each semester, the primary researcher and the instructor of the course asks the PSTs to write a response to three questions: (1) what is your definition of a good mathematics teacher?; (2) how do you describe your experience, beliefs, and attitudes toward mathematics learning during your K-12 schools and college?; and (3) what do you hope to learn from this methods course? Regarding the first question, most PSTs define a good mathematics teacher as someone who is patient, who can "show" multiple ways to solve a problem, who can make mathematics "fun", who has good knowledge of the subject matter, who understands and considers that children are different with varying abilities and varying learning styles, and someone who can "show" application of mathematics in the real world.

Relative to the second question, most PSTs expressed their negative experiences, attitudes, and beliefs toward mathematics learning during their K-12 schooling. For example, one PST stated:

Within my K-12 grades, I found my experience to be very difficult. I was having a difficult time interpreting and memorizing the material, which caused me to be placed within special classes where I was taught extra mathematics by computer. I internalized these situations that I am not good at math and I expected math to be always difficult after each year due to the little attention I received when I was struggling with math. I disliked mathematics because of the difficulty I had during these years. (PST Response to the Second Question) 
Similarly, another PST reflected on the negative experience they had in their K12 schooling:

My experiences in mathematics while in K-12 were not the most positive experiences. I remember that I was never given the opportunity to "explore", I was just taught through lectures and direct instructions. My expectations were to "learn" math and be successful, but I suppose I never truly learned most concepts. I never believed math would be very beneficial. (PST Response to the Second Question)

Although most PST participants expressed their negative experiences, attitudes, and beliefs toward mathematics, some PSTs shared positive experience, attitudes, and beliefs toward mathematics learning during elementary schools. For example, one PST wrote:

I loved math when I was in elementary school. I credit this to having parents who also enjoyed math, and good math teachers. Math content always came natural to me. In middle school my love and success in math continued. I was fortunate enough to have good math teachers throughout K-8 grade. I believed that math was an easily grasped subject. In high school, math became harder, but I still had some very good teachers. During my senior year of high school, I struggled the most, because I transferred schools and my math teacher was less than satisfactory. (PST Response to the Second Question)

All PSTs stated that their experiences, attitudes and beliefs, whether positive or negative, were significantly impacted by their teachers' instructional approaches and the teachers' expectations. As one PST put it:

I always enjoyed math in elementary school because I had good math teachers. My attitude towards mathematics began to change in middle school and high school because the way I was taught mathematics. I found that my teachers were not as engaging. Math became harder and I became discouraged. As a result, I did not have as good of an experience as in my elementary school years. My middle school and high school mathematics did not fully live up to my expectations because they were not fun. (PST Response to the Second Question)

Relative to college mathematics experiences, the PSTs' reactions were mixed. Some stated they had positive experiences due to the engaging nature of mathematics classroom environment and their instructors' expectations:

I learned a lot in my college mathematics classes. I took three math classes before taking this methods course. The professors always told us how important math is and had high expectations. I did not like being asked to communicate my answer verbally. However, little by little I began to enjoy it. (PST Response to the Second Question) 
However, not many PSTs shared these positive experiences.

In my freshman year my math instructor was so impatient with me. I started skipping so that I would not feel so judged and stupid. It got better later on, as I advanced in my program. I realized how important it was for me to be there, learning it. I really like math. (PST Response to the Second Question)

Negative experience in college can significantly influence a PST' self-confidence. Another PST stated how her positive attitudes turned negative because of her college mathematics experience.

In college, I brought with me the high expectations but my attitudes quickly changed from enjoyment back to resentment, as I did not enjoy the classes and was unable to connect with the instructors much. I was able to maintain high grades in math. I have taken three math classes before taking this class. I dreaded going to those math classes. (PST Response to the Second Question)

Relative to the third question, PSTs stated their expectations in many different aspects. They hoped to learn strategies for teaching mathematics. They wanted to have a better understanding of mathematical contents and pedagogy. They wanted to learn about current research on mathematics teaching, learning, and assessment. They hoped to learn how to incorporate technological tools such as calculators, computers, and Smartboards, into their teaching and learning of mathematics. They stated their desire to become good mathematics teachers who can inspire their students to having positive experience, attitudes, and beliefs toward mathematics learning.

In what follows, we describe the PSTs' critical reflections of their semester-long experiences in the mathematics methods course, their professional transformation, and their current concerns, struggles, and obstacles. The paper ends with discussions, implications, and recommendations regarding understanding and transforming complex processes of PSTs expectations, experiences, beliefs, and attitudes toward mathematics.

\section{PSTs' Critical Reflections}

Promoting reflectivity in the PSTs is an essential component of teacher development. As the semester evolved, the participating PSTs were engaged in various assignments and activities such as reading and reflecting on assigned articles and the textbook; classroom discussions on theoretical and practical issues raised by the instructor and the PSTs; problem solving and communication, writing lesson plans, presentations, and a final reflective paper. The PSTs participants reflected on several importance issues such as constructivism and the role of culture in a mathematics classroom, how children learn mathematics, the role of teachers in a mathematics classroom, authentic assessment, and their professional transformation. In what follows we describe each of the above. 
Constructivism and mathematics classroom culture. Classroom activities and discussions provided the PSTs opportunities to reflect on the limitations of the traditional teacher-centered way they learned mathematics (i.e., direct instruction). They became more aware and appreciative of constructivism as a new, effective way of learning mathematics and the notion of culture in the mathematics classroom. For example, one PST stated:

When teachers are dispensers of knowledge, it leaves little room for children to question facts that are presented by the teacher and often leads to misunderstanding in mathematical relationship. Critical thinking will be disabled because children will depend on their teachers to tell them the right answer from a one-sided perspective. (PST Reflection on Classroom Discussion)

Another PST mentioned the importance of knowing and understanding what children already know as a starting point for instruction.

Perhaps I am teaching kindergarten, and one student comes in with a plethora of learning experience, while the other has not had a single one. Do I start them both off on addition and wonder why the child without the experiences can't keep up? Perhaps I want to do a lesson on the metro parks and counting stones. Will the student who has never been to the metro parks be as engaged as the student who goes once a week with his grandma? This is where constructivism comes in. (PST Reflection on Classroom Discussion)

After listening to the above PST, another PST reflected on his learning experience, "As a child, I always thought something was wrong with me in regards to math. I was considered very slow in the math classroom. As I reflect know, I think it has a lot to do with the way I was taught math." (PST Reflection on Classroom Discussion)

The PST participants discussed the importance of mathematical connections with real world and teaching contents in meaningful and relevant contexts. For instance, one PST asserted, "Children who live in Florida may have a difficult time talking about snow/winter condition and measuring snow fall because they live in a state that normally has higher temperature than northern states. The children in Florida will not be able to relate to the idea of winter in the same sense that children from New York will be able to relate." (PST Reflection on Classroom Discussion) The PSTs discussed the value of culturally relevant mathematics. They stated that teachers should respect the cultural differences among their students. As one PST puts it:

So far, many of the readings and the overall structure of the course influenced my growth in this area because all of these showed me how to integrate students' culture into mathematics instruction. This will prove to be an important concept to have learned for the future when I am 
working as a teacher in any of the numerous culturally diverse school districts. These cultural ties to mathematics will give students more motivation and more of a solid platform as to why they should learn mathematics. (PST Reflection on Classroom Discussion)

On children learning mathematics. As the semester continued, the PSTs were involved in discussions of readings and classroom activities. The PSTs participants reflected on various issues such as the importance of problem solving, students writing, and cooperative learning. The PSTs noted that mathematics learning ought to be meaningful and focus on building young learners' problem solving abilities. The PSTs stressed that problem solving is an important component of mathematics learning. They mentioned that problem solving should encourage learners to focus on their thinking processes rather than the final product or solution. "A teacher whose goal is to facilitate their students' learning will promote problem solving as a process and allow them to use multiple points of entry and a myriad of solution strategies." (PST's Reflection on Readings and Classroom Activities) As another PST put it:

I will ask my students to write in their journals at least three times a week to give an explanation of what they learned during the classroom activities, how they can apply it outside of the classroom, and what areas that they may need improvement. This will also improve children's written communication skills as well as help those who struggle with verbally communicating their ideas or thought processes. Another method that I think is beneficial in assessing children understanding is writing down the steps needed for problem solving such as restating the question, drawing pictures (visual representations of what is being asked in the problem), communicating thoughts, and answering the question. (PST's Reflection on Readings and Classroom Activities)

Writing about mathematics is a strategy for showing problem-solving process suggested by many PSTs. Another PST agreed with the above statement by saying that as teachers, we do not really know what our students are thinking unless we provide them the opportunity to explore their mental processes:

I have come to learn the value of student writing. Writing and math are typically not seen as having a synonymous relationship. However, after learning about math essays and practicing how to write out answers to problems, I have come to find that writing in math allows you to reflect on your thinking, as well as, gives your teacher a portal into your thoughts and understanding. Assigning students thought provoking problems that require time and effort to complete allows them to engage in metacognitive processes related to math content. (PST's Reflection on Readings and Classroom Activities)

Through classroom actions and reflections of their own experiences learning mathematics, the participating PSTs observed benefits of problem solving and communication such as learners' metacognition (i.e. thinking about thinking), 
informing instruction, and assessing learners' understanding of mathematical ideas. In addition, they reflected on the importance of cooperative learning.

Importance of cooperative learning. In the methods course, PSTs reflected on the impact of cooperative group work on their own learning. They asserted how beneficial this approach could be for children to learn mathematics. They mentioned cooperative learning as a source for creating learning opportunities for all children. They stated multiple benefits of cooperative learning such as improving children's self-confidence, self-concept, relationships with their classmates, and communication skills with their peers from different ethnic backgrounds. As one PST stated:

Cooperative learning is a vital component in a student-centered classroom. It allows for students to work together in small groups on the same task. The collaboration is extremely effective because the students must explain their reasoning, understanding, and confusion. By helping students develop confidence through an affectionate environment, project-based learning, differentiation strategies, group collaboration, writing opportunities, and authentic assessments, my students will be far more confident in all content areas. My goal as a teacher is to provide my students with experiences which will create a loving relationship with school and specifically, with mathematics. (PST's Reflection on Readings and Classroom Activities)

On a teacher's role in mathematics classroom. The participating PSTs reflected on their current beliefs and attitudes toward mathematics instruction, assessment, classroom environment, and the appropriate use of manipulatives and technology for mathematical modeling and representation. Following we describe PSTs' current stated beliefs and attitudes toward mathematics teaching as they participated in and contributed to the classroom discussions and activities.

The most important factor, relative to role of teacher mentioned by the PSTs, was classroom environment and relationship between teacher and students. The PSTs stated that a transformative teacher is the one who has good content knowledge and pedagogical knowledge. This teacher has patience, values students thinking, and respects his/her students' thoughts, ideas, and opinions. This instructor also believes in their students' abilities and challenges them to think beyond their comfort zone. As one PST noted:

As a child, I always thought something was wrong with me in regards to math. In English, I was considered gifted, but then in math I was considered very slow. In this semester, so far, I learned there are many different, engaging strategies that a teacher can use to reach her students with varying abilities. These strategies would have benefitted me so much in my early education. Our earlier learning experiences directly correlate to our long-term success. What I come to know now is that as a teacher, I will get to know my students extremely well and build 
relationships with them, "you cannot teach me if you do not know me." I want to provide my students with positive math experience and confidence, which will travel with them throughout their lives. (PST's Reflection on Readings and Classroom Activities)

The PSTs' notion of classroom environment and the value of teacher/students relationships were mentioned by several PSTs throughout the semester. For example, one PST stated the following:

If I can develop personal relationships with all of my students, I will be better prepared as a teacher to create a curriculum connected to each of their unique learning styles and abilities. Understanding where each child comes from will also allow me to work with their best interest at heart, as I will be able to know what their lives are like, and where they may come from. Children are able to learn more comfortably when they have a personal relationship with their teacher, and it is my job to make sure I connect with each student in that way. (PST's Reflection on Readings and Classroom Activities)

The PSTs reflected on their prior learning experience in mathematics and changed their views regarding teacher's role as a facilitator of students' learning rather than dispenser of knowledge. One PST noted:

This is something that I have witnessed first-hand through this course and can speak to the effectiveness of it. This type of role offers a greater sense of equity in the classroom in that learning becomes more of a shared experience between students and teacher. For students, the classroom serves as a social environment in which the engagement and collaboration with other students promote critical thinking and acquisition of knowledge. The role of the teacher then becomes creating these simulated instances in which students can interact with each other. A way that this was achieved in this course was creating lesson plans that shared the same content for a variety of grade levels. (PST's Reflection on Readings and Classroom Activities)

The PST was referring to one of the course assignments relative to the PSTs' group project for developing and presenting their lesson plans that were appropriate for the pre-kindergarten through third grade levels. The group project component of the lessons refers to a coherent unit connecting prekindergarten lessons to kindergarten, first, second, and third grade.

Manipulatives and technology in the mathematics classroom. Another important factor that the PSTs reflected on, wrote about, and discussed throughout the semester was the relationship between mathematics teaching and the role of manipulatives and technology for mathematics instruction. The PSTs experienced using a variety of manipulatives such as Based-10-Blocks, Color Tiles, Pattern Blocks, Cuisenaire Rods, Tangrams, Geoboards, etc. during classroom activities, as well as technological tools and resources such as a 
Smartboard, computers, and calculators. One PST stated, "As a student in this class, I found using manipulatives to be very useful in solving problems, especially non-routine problems. It is a powerful way of visualizing mathematical problems." (PST's Reflection on Readings and Classroom Activities) The PSTs reflected on the value of manipulatives as instructional tools for teaching mathematics. They mentioned these tools provide learners with opportunities visualizing mathematical relationships through game playing and explorations. Furthermore, they stated that conceptual understanding of mathematical procedures requires moving from concrete manipulations of tools to abstract symbols. As one PST explained:

To effectively teach math so that young students grow to love and appreciate it, you must teach it in a way that is appealing to the group of students in your classroom. Math is often taught through the use of teacher-directed, drill and practice instruction. However, many young learners do not benefit from this type of instruction and often slip through the cracks because of it. Math should be visual and hands-on. Manipulatives are beneficial tools that teachers can use to enhance math instruction. These tools allow students to create their own visual representations of math problems such as fraction units. Visual representations allow students to gain new understanding for mathbased concepts that would regularly be difficult to understand. For example, a student could use rubber bands and geoboard to find the area of an irregular shape by creating a rectangle or square around the shape and seeing how many whole units and half units the irregular shape contains. Completing this type of problem on paper can be difficult, because the shape is one-dimensional and abstract, whereas, creating the shape with a manipulative transforms it into a concrete, tangible object. (PST's Reflection on Readings and Classroom Activities)

Similar to the PSTs' support for use of manipulatives was their reaction and reflections toward technology as an integral aspect of mathematics teaching and learning. As part of their course assignments, the PSTs participants searched, described, and evaluated many online materials relative to teaching and learning mathematics. Through the mixture of this research and classroom activities, they became more aware of the strengths and limitations of technological tools in mathematics classroom. They suggested that technology is an essential part of mathematics instruction, as one PST mentioned:

In my opinion, technology is going to be more present in our schools as the years go on. Therefore, I think that new-age teachers should critically analyze the pluses and minuses of the various website they are using before making it available to their students. Having said that, I believe young teachers ought to make their students technology literate, because many of them grew up during the boom of $21^{\text {st }}$ century technology. I believe that becoming a technology literate teacher is an essential part of educating young learners, and, in my opinion, technology is a positive 
addition to modern day classroom and will keep getting better as time goes on. (PST's Reflection on Readings and Classroom Activities)

Authentic assessment. As the semester evolved, the PSTs reflected and critically analyzed the limitations of standardized tests as the only way of evaluating learners' understanding and performance. They argued that the standardized tests "measure" what learners can not do, where the purpose of assessment is finding out what learners can do and using the information to enhance student understanding and adjust their instruction. One PST participant reflected on limitations of standardized tests:

I am not a fan of the increased focus on standardized testing in schools and I believe that schools should be reformed and give less focus on this matter. Standardized testing gives schools and states a small snapshot of understanding of what children know, but it doesn't assess the whole child. Sometimes children may answer multiple-choice questions correctly through guessing. Scorers will never know that a child guessed on that particular question, but the child is either punished or rewarded based on a guess. I think it is very important for the process to be assessed and not the product. (PST's Reflection on Readings and Classroom Activities)

The PST participants were in favor of more authentic assessment instead of standardized tests. One PST asserted that the best type of assessment is authentic because it allows him to gauge his students for understanding of mathematical ideas as well as their confusions. He described his authentic assessment approach this way:

One example of the type of assessment I will conduct is students creating a concept map. With a group, they will have to create a concept map on a big poster to explain their understanding of the lesson we did. Another example I have for an authentic assessment is role-playing. Perhaps students are pretending to be geologist searching for lost treasure, and having to scale a map to find their route. Role-playing provides students with confidence, accountability, and engagement. (PST's Reflection on Readings and Classroom Activities)

The PST participants stressed that assessment is a key component to any type of instruction. A shared notion is that assessment ought to be used more for formative instead of summative purposes. Specifically, PSTs mentioned that assessment allows a teacher to gather data, make necessary changes to instruction, learn more about their students, and learn their students' strengths and weaknesses. PSTs also indicated that effective assessment requires multiple approaches. As one PST explained:

Assessment can be done in a variety of different ways. I believe that the most effective ways to assess are creating comprehensive portfolios, including built in formative and summative assessment into lessons, and 
taking notes on the student's abilities and performance in the classroom. Assessment in a mathematics classroom should go beyond homework assignments, drill and practice activities, and tests. (PST's Reflection on Readings and Classroom Activities)

\section{PSTs' Transformation of Beliefs and Attitudes}

The PSTs' semester journey in the mathematics methods course provided them with opportunities to reflect and reevaluate their prior assumptions, beliefs, and attitudes relative to what mathematics is, how students learn mathematics, the role of teachers, classroom culture, authentic assessment, the role of manipulatives, and technology in mathematics classroom. At the end of the semester, they presented their concerns, struggles, and obstacles. One PST wrote:

My main concern and struggle in teaching mathematics is the fact that I have struggled with learning mathematics throughout my schools. It is not my strong suit. Nevertheless, when I put my greatest effort into learning and understanding mathematical concepts, I am successful. I feel that even though I lack confidence in math due to years of being told I was no good at it, I will overcome that insecurity for the good and education of my future students. I truly care about the education and well-being of my students. I care about their experiences, background, and learning process. (PST Final Reflective Paper)

The PST stated that her passion for teaching would always lead her to face her obstacles and find ways to solve problems in the future. She stated "teaching mathematics is an act of love and I am determined to show this act of love to my students" (PST Final Reflective Paper). Another PST stated her concern in regards to her level of experience relative to creating a classroom climate conducive to learning for all students. "I think I have knowledge that is required to teach math content. However, I am concerned with my ability to teach it to children" (PST Final Reflective Paper). Several PSTs clearly indicated their change of beliefs as a transformative process that will effect their expectations for future teaching careers. One PST reflected on her semester-long learning experience and indicated the desire to become a teacher who can transform experiences and beliefs of his/her future students:

This course has taught me how to encourage children to think for themselves and to make connections to the world around them. As a future teacher, I hope to influence children to think outside of the box and explore different ways to solve mathematical problems. With the use of technology, manipulatives, games, storytelling, and other fun activities, math should never be viewed as a subject that is hard to accomplish. Negative attitudes have a negative impact on the way that one learns math and it will always appear to be difficult until their mindset is changed. I've also realized that teaching math calls for someone who is dedicated to teaching young children and constantly 
learning new methods to better meet the needs of children learning math. (PST Final Reflective Paper)

Other PSTs shared similar concerns, struggles, and obstacles with respect to teaching mathematics including motivating learners and finding an instructional balance that is engaging for students, yet comprehensive in terms of the distribution of contents. This is something that they are in the process of figuring out how to balance. Many PSTs asserted that they would continue to reflect on their teaching and seek out resources to create a more engaging classroom experience for their students. One PST summed it up:

Going into this class, one concern I had was that I had trouble with math growing up. When I was younger, math was one of my weakest categories in school. I had fear when I would think about being an educator that how can I teach children when I don't always understand math myself? This is still a conflict I am trying to solve, but I have learned from this course that teachers need to be confident in themselves in order to teach students. I know I am able to teach the math this is required in these young grades, so I learned a lot about trusting myself as a teacher and knowing I can do this. One piece of information I really took with me from this class was something you [the instructor of the course] taught us on the first day. I used to often say, "I hate math" or "math is the worst subject," and it was a worry I had because I was not sure I was going to be able to teach it. On the first day, you told us that a child does not want to learn from a teacher who hates what they are teaching, and I have taken that with me. Is math my favorite? No, but the children don't need to know this. It will only discourage their learning. No child wants to learn from a teacher who does not want to teach the material. I think that is the most valuable lesson I learned, and I will take it with me. As a teacher, we must always be evaluating ourselves and trying to learn what we can do differently. Learning does not stop after earning a college degree. I believe we are life-long learners. (PST Final Reflective Paper)

Overall, although the PSTs expressed some concerns, struggles, and obstacles relative to their new careers as teachers, especially when it involves mathematics content knowledge and pedagogical knowledge for specific grade levels, they were optimistic regarding facing the complexities of teaching and learning and were determined to resolve those obstacles or conflicts in their future teaching mathematics. It seems that some of them also learned to become self-aware of their attitudes and beliefs as well as the causes and consequences and use selfregulation strategies (e.g., self-evaluation and self-monitoring) to increase positive experiences, maintain positive attitudes and beliefs, and rebuff negative attitudes and beliefs.

\section{Discussions, Implications, and Recommendations}

Pre-service teachers' reflections on their mathematical experiences, expectations, attitudes, and beliefs in a constructivist classroom might bring about more 
lasting change to their mathematics beliefs, self-efficacy, and teaching efficacy, which might continue on into their teaching careers. Briley (2012) suggested mathematics content courses for elementary pre-service teachers ought to be taught in a more constructivist manner so that pre-service teachers can develop beliefs that are consistent with the NCTM reform movements. While ambitious goals have been set in the area of mathematics reforms, teacher education and professional development have been largely unsuccessful in educating teachers in line with such suggested reforms (Simon, 2013). Furthermore, pre-service teachers showed a general desire to teach in an informed way, different from how they learned mathematics in schools, but this is intimidating for some, as it requires a restructuring of their mathematics beliefs and requires a deep level of understanding of how children learn mathematics (Jong \& Hodges, 2013).

Grounded in constructivist theories and using a qualitative approach, the present study explored a group of pre-service teachers' transformative experience taking a semester-long methods course in mathematics. Through a series of structured reflective activities, the PST participants shared their previous mathematics learning experiences and their transforming beliefs, attitudes, and expectations regarding role of teacher and students in mathematics classroom, classroom culture, authentic assessment, role of manipulatives, and technology in mathematics classroom. There is much evidence that most PSTs gradually developed a more sophisticated understanding of mathematics learning process, which also lead them to fully embrace a constructivist approach. A recurring theme is that PSTs strongly opposed the traditional, teacher-centered mathematics classroom characterized by direction instruction, lectures, and drill and practice where students are directed to memorize but struggle with conceptual understanding. Instead, they favored a student-centered classroom where the teacher focuses on facilitating students' mathematics thinking by engaging them in problem solving, visualization, writing and communication, etc.

The findings of the study suggest that PSTs' critical reflections on the assigned readings, classroom discussions, and activities are responsible for transforming their beliefs and attitudes toward mathematics teaching and learning. PST participants were able to reflect, analyze, and evaluate their mathematics learning experiences from elementary school to college and become aware of how their beliefs and attitudes regarding important aspects of mathematics teaching and learning had evolved over the years through either positive and negative experiences with different teachers. Such reflections not only helped the PSTs to make sense of their past experiences, but also enabled them to reconstruct their existing beliefs and attitudes and develop new expectations for mathematics teaching that are more consistent with their reconstructed beliefs and attitudes. Many of our PST participants reached a new level of understanding of the teacher's role in building relationships with learners from different cultural backgrounds and that the teacher's understanding of different students learning styles is crucial for creating learning opportunities for all learners. Another major theme in their transformation involves understanding that as a mathematics teacher, believing in children's abilities for doing 
significant mathematics and setting clear goals and high expectations for all learners is pivotal for turning negative attitudes, beliefs, and experiences to positive. One PST participant expressed:

I want to apply myself to the "Big Picture Education" model. This model includes teaching to attain long-term, meaningful goals. It focuses on teaching children based on all areas of development, not just cognitive processes. It also focuses on real-world applications, rather than out-ofcontext, assumptive lessons. I think that this is the only way to truly teach students. However, I must stay committed to this approach and not fall into poor practices that steer away from this model. I also want to approach teaching in a way that creates personal goals for students that address all types of learning. Creating goals that are specific to all parts of the student's education and well-being are essential to effective teaching. Students should reach goals based on emotional and social facets of their lives, as well as process goals based on subjects. I think this approach ensures that students are receiving their best learning. To achieve this goal consistently, I must consistently create goals for students based on their individual needs. (PST Final Reflective Paper)

Interestingly, the PSTs' transformative experiences seemed to resonate with the constructivist beliefs and practices incorporated and modeled by the primary researcher and course instructor in the classroom. There is evidence that our participants had a general agreement toward the end of the semester that establishing goals for both teacher and learners, negotiating expectations, communicating role of teacher and learners in mathematics classroom, believing in learners' abilities for doing mathematics, and building caring relationships with learners are essential for educating all children in today's society.

This research study is significant for two important reasons. First, as Simon (2013) noted, modest changes in teacher education fail to address PSTs' major assimilatory structures, or the core conceptions, including actions, knowledge, values, beliefs, feelings, and skills, that contribute to the teaching of mathematics. This research study supports Simon's assertions and describes how the PSTs' critical reflections, as an essential component of teacher development, and analysis of their prior experiences, expectations, beliefs, and attitudes provide them the opportunities to deconstruct their prior assumptions and reconstruct them from different perspectives (i.e. change in epistemology). Second, the PSTs' epistemological shift from teacher-centered perspective to constructivism is more than a teaching strategy but rather an essential component of praxis (i.e. action and reflection). This was particularly evident in their changed understanding of the role of assessment as a tool for reward and punishment to a tool for informing instruction and improving learning. What was also relevant was the PSTs' growing emphasis on problem solving and encouraging and facilitating mathematics thinking processes instead of the final product or solution in a student-centered classroom.

The present study has significant implications for teacher education practices. 
We suggest that the participating PSTs' sustained transformation of beliefs and attitudes requires ongoing professional development opportunities and supports as they start teaching in various school settings during their studentteaching and first few years of their professional lives. In addition, providing the PSTs with mentoring opportunities is an essential component of teachers' professional development relative to sustaining teachers' transformations. Connecting the PSTs with transformative mentor teachers, so that they can share ideas and exchange information with one another, is vital for reforming mathematics education. This kind of teachers' practices is aligned with reform movement suggested by NCTM.

Another implication of this research study is to demonstrate constructivist epistemology into action for the mathematics education community as well as a broader educational research community. The first group might be familiar with methods for establishing a constructivist-oriented mathematics classroom. The second group of readers might understand the principles of constructivism but could possibly find it difficult to envision a mathematics classroom that is structured in accordance with constructivist principles. Providing these two groups opportunity to engage in praxis (i.e. action and reflection) may create a milieu for crossing the boundaries of their own familiar cultural contexts in order to meet the needs of diverse students in their own classrooms.

Finally, our study has some limitations and future research is warranted to further investigate transformative experiences for different populations in different settings. As far as teacher preparation programs are concerned, we recommend more follow-up research relative to these practicing teachers' expectations, beliefs, and attitudes toward mathematics as they start teaching in their own classrooms. It is possible that engaging pre-service teachers and new in-service teachers in becoming action researchers in their own classroom may benefit the school and university partnership as transforming learning communities. Furthermore, for better understanding of pre-service and inservice teachers' transforming expectations, attitudes, and beliefs, mixed methods research that combines qualitative and quantitative approaches is needed. We believe that mixed methods research benefits from the strengths of both quantitative and qualitative research and therefore provide a better perspective for understanding, analyzing, and interpreting the complexity of teacher change and mathematics education reform in general.

\section{Acknowledgment:}

A short draft of this research paper was presented at the proceedings of $14^{\text {th }}$ International Conference of the Mathematics Education for the Future project: Challenges in mathematics Education for the Next decade, September 10-15. 2017, Balatonfüred, Hungary.

We would like to thank Mr. Nicholas M. Chmura for his time regarding editing of the of this manuscript. 


\section{Endnote:}

We obtained the Cleveland State University Institutional Review Board's (CSU, IRB) approval for conducting this research study. This paper has not been previously published, nor is it before another journal for consideration.

\section{About the Authors:}

Roland Pourdavood is a professor of mathematics education at Cleveland State University, Department of Teacher Education. His research interests include mathematics teachers' dialogue and reflection for transformation and school reform. In addition, he focuses on cultural diversity, sociocultural aspects of education, and emancipatory action research for personal and social praxis.

Xiongyi Liu is an associate professor of educational psychology at Cleveland State University, Department of Curriculum and Foundations. Her research interests include motivation, self-regulation, collaborative learning, and peer assessment. Her research has a special focus on computer based learning environments.

\section{References}

Bogdan, R. \& Biklen, S. (1982). Qualitative research of education: An introduction to theory and methods. Boston, MA: Allyn and Bacon.

Briley, J. S. (2012). The relationships among mathematics teaching efficacy, mathematics self-efficacy, and mathematical beliefs for elementary pre-service teachers. Issues in the Undergraduate Mathematics Preparation of School Teachers, 5, 1-13.

Burton, M. (2012). What is math? Exploring the perception of elementary pre-service teachers. Issues in the Undergraduate Mathematics Preparation of School Teachers, 117.

Cardetti, F., \& Truxaw, M. P. (2014). Toward improving the mathematics preparation of elementary preservice teachers. School Science and Mathematics, 114(1), 1-9. doi: https:// doi.org/10.1111/ssm.12047

Cobb, P. (1994, Oct.). Where is mind? Constructivist and sociocultural perspectives on mathematical development. Educational Researcher, 23, 13-20. doi: https:// doi.org/10.2307/1176934

Cobb, P., \& Yackel, E. (1996). Constructivist, emergent, and sociocultural perspectives in the context of developmental research. Educational Psychologist, 31 (3/4), 175-190. doi: https://doi.org/10.1207/s15326985ep3103\&4_3

Dreher, A., \& Kuntze, S., (2015). Teachers' professional knowledge and noticing: The case of multiple representations in the mathematics classroom. Educational Studies in Mathematics, 88(1), 89-114. doi: https://doi.org/10.1007/s10649-0149577-8

Dreher, A., Kuntze, S., \& Lerman, S. (2016). Why use multiple representations in the mathematics classroom? Views of English and German Preservice Teachers. International Journal of Science \& Mathematics Education, 14, 363-382. doi: https:// doi.org/10.1007/s10763-015-9633-6

Garcia, I. \& Pacheco, C. (2013). A constructivist computational platform to support mathematics education in elementary school. Computers \& Education, 66, 25-39. doi: https://doi.org/10.1016/j.compedu.2013.02.004

Guba, E. G. \& Lincoln, Y. S. (1994). Comparing paradigm in qualitative research. In N. K. Denzin \& Y. S. Lincoln (Eds.), Handbook of Qualitative Research (pp.105-117). Thousand Oaks, CA: Sage.

Guba, E. G \& Lincoln, Y. S. (1989). Fourth generation evaluation. Newbury Park, CA: Sage . 
Hennessey, M. N., Higley, K., \& Chestnut, S. R. (2012). Persuasive pedagogy: A new paradigm for mathematics education. Educational Psychology Review, 24(2), 187204. doi: https://doi.org/10.1007/s10648-011-9190-7

Itter, D. \& Meyers, N. (2017). Fear, loathing and ambivalence toward learning and teaching mathematics: Preservice teachers' perspectives. Mathematics Teacher Education \& Development, 19(2), 123-141.

Jong, C., \& Hodges, T.E. (2015). Assessing attitudes toward mathematics across teacher education contexts. Journal of Mathematics Teacher Education, 18, 402-425. doi: https://doi.org/10.1007/s10857-015-9319-6

Jong, C., \& Hodges, T.E. (2013). The influence of elementary preservice teachers' mathematical experiences on their attitudes towards teaching and learning mathematics. International Electronic Journal of Mathematics Education, 8(2-3), 100122.

Kalchman, M. (2011). Preservice teachers' changing conceptions about teaching mathematics in urban elementary classrooms. Journal of Urban Mathematics Education, 4(1), 75-97.

Lincoln, Y. S. \& Guba, E. G. (1985). Naturalistic inquiry. Beverly Hills, CA: Sage.

McCracken, G. (1988). The long interview. Newbury Park, CA: Sage. doi: https:// doi.org/10.4135/9781412986229

McLeof, D.B. \& Ortega, M. (1993). Affective issues in mathematics education. In P. S. Wilson (Ed.), Research Ideas for the Classroom: High School Mathematics (pp. 21-36). New York: McMillan.

National Council of Teachers of Mathematics. (2000). Principles and standards for school mathematics. Reston, VA: NCTM.

National Council of Teachers of Mathematics. (1995). Assessment standards for School mathematics. Reston, VA: NCTM.

National Council of Teachers of Mathematics. (1991). Professional standards for teaching mathematics. Reston, VA: NCTM.

National Council of Teachers of Mathematics. (1989). Curriculum and evaluation standards. Reston, VA: NCTM.

Narli, S. (2011). Is constructivist learning environment really effective on learning and long-term knowledge retention in mathematics? Example of the infinity concept. Educational Research and Reviews, 6(1), 36-49.

Özmantar, M. F., Akkoc, H., Bingolbali, E., Demir, S., \& Ergene, B. (2010). Pre-service mathematics teachers' use of multiple representations in technology-rich environments. EURASIA Journal of Mathematics, Science \& Technology Education, 6(1), 19-36. doi: https:// doi.org/10.12973/ejmste/75224

Pappas, T. (1986). The Joy of Mathematics: Discovering Mathematics All Around You. San Carlos, CA: Wide World Publishing/Tetra.

Simon, M. A. (2013). Promoting fundamental change in mathematics teaching: A theoretical, methodological, and empirical approach to the problem. ZDM Mathematics Education, 45, 573-582. doi: https://doi.org/10.1007/s11858-0130486-6

Stohlmann, M., Cramer, K., Moore, T., \& Maiorca, C. (2014). Changing pre-service elementary teachers' beliefs about mathematical knowledge. Mathematics Teacher Education \& Development, 16(2), 4-24.

Tsuruda, G. (1994). Putting it together: Middle School. Portsmouth, NH: Heinemann.

Xenofontos, C. \& Kyriakou, A. (2017). Prospective elementary teachers' beliefs about collaborative problem solving and dialogue in mathematics. Mathematics Teacher Education \& Development, 19(2), 142-158.

Zain, S.F.H.S., Rasidi, F.E.M., \& Abidin, I.I.Z. (2012). Student-centered learning in mathematics: Constructivism in the classroom. Journal of International Educational Research, 8(4), 319-328. doi: https://doi.org/10.19030/jier.v8i4.7277 